\title{
PEMBERIAN ASI EKSKLUSIF PADA IBU YANG MEMILIKI BAYI UMUR 6-11 BULAN DI WILAYAH KERJA PUSKESMAS KECAMATAN TAMBANG KABUPATEN KAMPAR TAHUN 2015
}

\author{
EXSCLUSIVE BREASTFEEDING WITH MOTHER HAVE 6-11 MONTH INFANT IN \\ HEALTH WORK AREA OF HEALTH CENTER DISTRIC TAMBANG, KAMPAR 2015
}

\author{
Siti Maulidaniah, \\ Akademi Kebidanan Tuti Rahayu, Bagansiapiapi \\ email : nia.291087@gmail.com
}

\begin{abstract}
ABSTRAK : Organisasi dunia yang bergerak dalam perlindungan anak (UNICEF) menyatakan pada sebuah analisa intervensi ditemukan, yaitu pemberian ASI selama 6 bulan dapat menyelamatkan 1,3 juta bayi diseluruh dunia termasuk $22 \%$ nyawa yang melayang setelah kelahiran. Di Indonesia cakupan pemberian ASI eksklusif masih rendah dan menunjukkan perkembangan yang sangat lambat. Di Kabupaten Kampar pada tahun 2009 cakupan pemberian ASI eksklusif hanya mencapai angka 19,53\%.Tujuan penelitian ini adalah diketahuinya Proporsi dan Faktor-faktor Yang Berhubungan Dengan Pemberian ASI Eksklusif Pada Ibu Yang Memiliki Bayi Umur 6-11 Bulan di Wilayah Kerja Puskesmas Kecamatan Tambang Kabupaten Kampar tahun 2015, yaitu : Pengetahuan, Sikap, Keluarga, Petugas Kesehatan, Pekerjaa, Pendidikan, Paritas dan Umur. Penelitian ini bersifat Kuantitatif Analitik Observasional dengan jenis desain Analytic Cross Sectional. Dengan jumlah populasi penelitian 669 orang dan sampel sebanyak 203 orang yang diambil secara Systematic random sampling. Analisis data dilakukan secara univariat, bivariat dengan Uji Chi Square dan multivariat dengan regresi logistik ganda. Hasil penelitian menunjukkan proporsi Ibu dengan ASI Eksklusif 28 orang (13,79\%). Hasil multivariat yang berhubungan sifnifikan dengan pemberian ASI Eksklusif yaitu; Sikap POR 4,0 (CI:95\% 1,52710,481), Pengetahuan POR 2,9 (CI:95\% 1,179-7,229) dan Dukungan Keluarga POR 2,9 (CI:95\% 1,206-7,222). Disarankan bagi ibu dan keluarga ibu untuk memberikan ASI secara Eksklusif kepada bayinya dan tidak mudah terpengaruh pada iklan susu formula.
\end{abstract}

\section{Kata Kunci $\quad$ : Pemberian ASI Eksklusif, Sikap, Pengetahuan, Dukungan keluarga}

ABSTRAC: UNICEF confirm thats an intervension analysis founds, breastfeeding up to 6 months can save lifes of 1,3 million infants around the world including $22 \%$ of deathly infants after born process. To Indonesian Exclusive breastfeeding have low rate with a slowly growth. In 2009 Kampar Distric number of Exclusive breastfeeding only 19,53\%. The research aims at to founds the number of exclusive breastfeeding and to determine the factors depends to Exclusive Breastfeeding by mother haves 6-11 months infants in Health Work Area of Health Center Distric Tambang, Kampar in 2015, there are : Attitude, knowledge, family suporting, health team supporting, Jobs, formal Institute, parity and age.The reserch using a quantatives Analitical observation with Analytic Cross Sectional form design. With a number of population is 669 represent by 203 sample doingby systematic random sampling. Data analysis performed using univariate, bivariate with Chi Square test and multivariate with Regression Binary Logistic.Result of research shown that proportion of mothers doing Exclusive breastfeeding is 28 persons and not doing 175 (86,21\%). There are 3 variables associated to Exclusive berastfeeding they are : Attitude POR 4,0 (CI:95\% 1,527-10,481), Knowledge POR2,9 (CI:95\% 1,179-7,229) and Family supporting POR 2,9 (CI:95\% 1,206-7,222). Recomended to those mother and the family to know the spectaculer advantages of Exclusive breastfeeding and not easy to believe the formula milk advertising.

Keywords $\quad$ : Mother breast milk (ASI), Attitude, Knowledge, Family Support 


\section{A. PENDAHULUAN}

Air Susu Ibu (ASI) adalah makanan yang paling sempurna bagi bayi. ASI mengandung semua nutrisiyang diperlukan untuk tumbuh dan berkembang selama sekurang-kurangnya 6 bulan pertama. Pemberian ASI tanpa makanan dan minuman tambahan lain pada bayi berumur 0 sampai 6 bulan disebut ASI Eksklusif (Rahmawati, 2010).

United Nation Childrens Funds (UNICEF) dan World Health Organization (WHO), menyebutkan bahwa dalam rangka menurunkan angka kesakitan dan kematian anak, direkomendasikan sebaiknya anak hanya disusuiair susu ibu selama palingsedikit 6 bulan.Makananpadatseharusnyadiberikansesudah bayi berumur 6 bulandanpemberian ASIdilanjutkan kembali sampai anak berumur 2 tahun (WHO, 2009).

Data UNICEF tersebut didapatkan 30.000 kematian bayi di indonesia dari 10 juta kematian anak balita di dunia setiap tahunnya. UNICEF juga menyebutkan bukti ilmiah terbaru yang juga dikeluarkan Journal Paediatrics, bahwa bayi yang diberikan susu formula memiliki kemungkinan untuk meninggal dunia pada bulan pertama kelahiran dan peluang itu 25 kali lebih tinggi daripada bayi yang disusui oleh ibunya secara eksklusif (UNICEF, 2011).

Berbagai sumber menyebutkan bahwa cakupan pemberian ASI Eksklusif di Indonesia masih rendah dan menunjukkan perkembangan yang sangat lambat. Pada tahun 2013 cakupan pemberian ASI Eksklusif sebesar 54,3\%, angka ini sedikit meningkat bila dibandingkan dengan tahun 2012 yaitu sebesar 48,6\%, namun angka ini masih jauh dibawah target yaitu $80 \%$ (Depkes RI, 2013).

Cakupan pemberian ASI Eksklusif di Riau juga masih menunjukkan angka dibawah target. Hal ini dapat dilihat dari sebuah data yang diperoleh pada tahun 2013 yaitu sebesar 55,9\% (Depkes RI, 2013). Di Kabupaten Kampar pada tahun 2013 dari 12 Kabupaten di Riau,Kampar memiliki angka pemberian ASI Eksklusif paling rendah yaitu 39\% dan tahun 2014 kembali mengalami penurunan menjadi 54,9\% (Dinkes Kampar, 2015).

Adapun faktor-faktor yang mempengaruhi pemberian ASI Eksklusif adalah pengetahuan, dukungan petugas kesehatan dan pekerjaan, ada beberapa faktor lain yang juga sangat berpengaruh pada pemberian ASI Eksklusif, misalnya ibu takut kehilangan daya tarik sebagai seorang wanita karena dengan menyusui akan membuat bentuk payudara menjadi kurang menarik, ibu sering merasa kurang percaya diri bahwa bayinya tidak akan tumbuh dengan baik jika hanya diberi ASI, faktor dari bayi sendiri dan juga faktor lingkungan, misalnya ibu bekerja atau meniru teman yang juga memberikan susu formula kepada anaknya (Roesli, 2005).

Puskesmas Kecamatan Tambang adalah Puskesmas yang memiliki jumlah bayi terbayak jika dibandingkan dengan 11 puskesmas lain yang ada di Kabupaten Kampar tetapi cakupan pemberian ASI Eksklusifnya masih cukup jauh dari target. Selain itu, penelitian tentang ASI Eksklusif di Puskesmas Kecamatan Tambang ini belum pernah dilakukan sebelumnya. Berdasarkan survei pendahuluan yang dilakukan di Puskesmas Kecamatan Tambang, cakupan pemberian ASI Eksklusif pada bayi 0-6 bulan pada tahun 2013 dari 429 bayi ada 332 bayi atau 77,4\% yang sudah diberikan ASI Eksklusif, namun di tahun 2014 mengalami penurunan dari 669 bayi hanya 341 bayi atau 51\% yang mendapatkan ASI Eksklusif. Angka ini jauh dari taget pemberian ASI Eksklusif yaitu 100\% (Puskesmas Kecamatan Tambang, 2015).

Oleh sebab itu, maka penulis merasa tertarik untuk meneliti tentan "FaktorFaktorYang Berhubungan Dengan Pemberian ASI Eksklusif Pada Ibu Yang Memiliki Bayi Umur 6-11 Bulan Di Wilayah Kerja Puskesmas Kecamatan Tambang Kabupaten Kampar Tahun 2015". 


\section{B. METODE PENELITIAN}

\section{Jenis dan Desain Penelitian}

Penelitian ini bersifat analitik kuantitatif dengan jenis desain Analitic cross sectional study. Dengan nama variabel independen dan variabel dependen yang ditanyakan dalam waktu yang sama kepada responden (Lapau, 2012) yang berada diwilayah kerja Puskesmas Kecamatan Tambang Kabupaten Kampar tahun 2015.

\section{Populasi dan Sampel Penelitian}

Populasi dari penelitian ini adalah seluruh ibu yang memiliki bayi usia 6-11 bulan yang diperoleh dari data bidan yang bertugas di desa pada wilayah kerja Puskesmas Kecamatan Tambang tahun 2015 yaitu sebanyak 669 orang.Pada penelitian ini diambil sampel sebanyak 203 orang dengan menggunakan prosedur Systematic Random Samping.

\section{Teknik Pengolahan Data dan Analisa Data}

Analisis datadilakukan secara bertahap yang meliputi analisis univariat, bivariat meliputi uji Chi-Square dan Analisis Multivariate yang dilakukan adalah Uji Regresi Logistik Ganda.

C. HASIL

Analisis Univariat

Hasil analisis univariat variabel dependen menunjukkan bahwa proporsi ASI Eksklusif di Wilayah Puskesmas Tambang adalah 13,79\%.

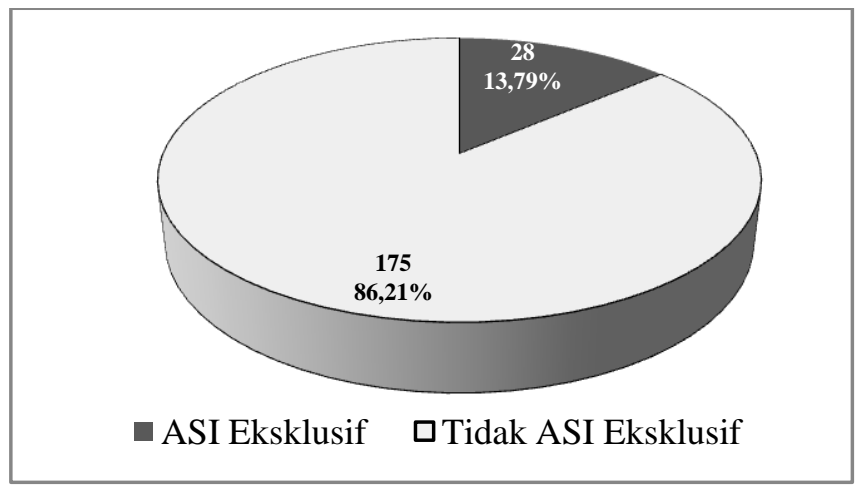

\section{Gambar 4 Proporsi Pemberian ASI Eksklusif pada bayi Umur 6-11 bulan di Puskesmas Kec. Tambang Kabupaten Kampar.}

\section{Analisis Bivariat}

Sedangkan analisis univariat dari variabel independen menunjukkan $60,6 \%$ ibu yang Pengetahuan Rendah, 51,2\% ibu yang Sikap Negatif, 62,6\% ibu yang dengan dukungan keluarga Tidak Mendukung, 23,2\% ibu yang Petugas Kesehatan Tidak Mendukung, 24,6\% ibu yang Status Pekerjaan Bekerja, 64,5\% ibu yang Paritas Primipara, 43,8\% ibu yang Pendidikan Rendah dan $68 \%$ ibu yang Umur $\geq 30$ tahun.

Hasil uji bivariat menunjukkan bahwa ada ada 5 variabel independen yang berhubungan signifikan dengan Pemberian ASI Eksklusif, yang dapat dijelaskan sebagai berikut, Ibu dengan Sikap negatif berhubungan 4,3 kali (C.I.95\% POR =1,774 -10,885) untuk 
tidak memberikan ASI Eksklusif bila dibandingkan dengan ibu yang memiliki Sikap Positif.Ibu dengan Pengetahuan rendah berhubungan3,9 kali (C.I.95\% POR $=1,683$ 9,248)untuk tidak memberikan ASI Eksklusif bila dibandingkan dengan ibu yang memiliki Pengetahuan tinggi.Ibu dengan Dukungan Keluarga tidak mendukung berhubungan3,6kali (C.I.95\% POR=1,576-8,366) untuk tidak memberikan ASI Eksklusif bila dibandingkan dengan ibu yang Dukungan Keluarga yang mendukung.Ibu dengan Umur $\geq 30$ tahun berhubungan2,8kali (C.I.95\% POR =1,281 - 6,497)untuk tidak memberikan ASI Eksklusif bila dibandingkan dengan ibu yang memilikiumur $<30$ tahun.Ibu dengan Paritas Primapara berhubungan 2,2kali (C.I.95\% POR $=1,000-5,247$ ) untuk tidak memberikan ASI Eksklusif bila dibandingkan dengan ibu yangParitas Multipara (lihat tabel 1)

Tabel 1 HubunganVariabelIndependen dengan Pemberian ASI Eksklusif

\begin{tabular}{|c|c|c|c|c|c|c|c|}
\hline \multirow{3}{*}{$\begin{array}{c}\text { Variabel Independen } \\
\text { dan Kategori }\end{array}$} & \multicolumn{7}{|c|}{ Pemberian ASI Eksklusif } \\
\hline & \multicolumn{2}{|c|}{$\begin{array}{l}\text { Tidak ASI } \\
\text { Eksklusif }\end{array}$} & \multicolumn{2}{|c|}{ ASI Eksklusif } & \multirow{2}{*}{$\begin{array}{l}\text { Total } \\
\mathbf{n}(\%)\end{array}$} & \multirow[t]{2}{*}{$\begin{array}{c}\mathbf{P} \\
\text { Value }\end{array}$} & \multirow[t]{2}{*}{$\begin{array}{c}\text { POR } \\
(95 \% \mathrm{CI}) \\
\end{array}$} \\
\hline & $\mathbf{N}$ & $\%$ & $\mathbf{N}$ & $\%$ & & & \\
\hline Pengetahuan & & & & & & & 3,945 \\
\hline Rendah & 114 & $(92,7)$ & 9 & $(7,3)$ & $123(100)$ & 0,001 & $1,683-$ \\
\hline Tinggi & 61 & $(76,3)$ & 19 & $(23,8)$ & $80(100)$ & & 9,248 \\
\hline Sikap & & & & & & & 4,394 \\
\hline Negatif & 104 & $(93,7)$ & 7 & $(6,3)$ & $111(100)$ & 0,001 & $1,774-$ \\
\hline Positif & 71 & $(77,2)$ & 21 & $(22,8)$ & $92(100)$ & & 10,885 \\
\hline Dukungan Keluarga & & & & & & & 3,631 \\
\hline Tidak Mendukung & 117 & $(92,1)$ & 10 & $(7,9)$ & $127(100)$ & 0,002 & $1,576-$ \\
\hline Mendukung & 58 & $(76,3)$ & 18 & $(23,7)$ & $76(100)$ & & 8,366 \\
\hline Petugas Kesehatan & & & & & & & 1,955 \\
\hline Tidak Mendukung & 43 & $(91,5)$ & 4 & $(8,5)$ & $47(100)$ & 0,231 & $0,642-$ \\
\hline Mendukung & 132 & $(84,6)$ & 24 & $(15,4)$ & $156(100)$ & & 5,949 \\
\hline Status Pekerjaan & & & & & & & 3,060 \\
\hline Bekerja & 47 & $(94,0)$ & 3 & $(6,0)$ & $50(100)$ & 0,066 & $0,883-$ \\
\hline Tidak Bekerja & 128 & $(83,7)$ & 25 & $(16,3)$ & $153(100)$ & & 10,609 \\
\hline Paritas & & & & & & & 2,291 \\
\hline Primapara & 98 & $(90,7)$ & 10 & $(9,3)$ & $108(100)$ & 0,046 & $1,000-$ \\
\hline Multipara & 77 & $(81,1)$ & 18 & $(18,9)$ & $95(100)$ & & 5,247 \\
\hline Pendidikan & & & & & & & 2,154 \\
\hline Rendah & 81 & $(91,0)$ & 8 & $(9,0)$ & $89(100)$ & 0,079 & $0,901-$ \\
\hline Tinggi & 94 & $(82,5)$ & 20 & $(17,5)$ & $114(100)$ & & 5,153 \\
\hline Umur & & & & & & & 2,885 \\
\hline$\geq 30$ tahun & 125 & $(90,6)$ & 13 & $(9,4)$ & $138(100)$ & 0,008 & $1,281-$ \\
\hline$<30$ tahun & 50 & $(76,9)$ & 15 & $(23,1)$ & $65(100)$ & & 6,497 \\
\hline Jumlah & 175 & $(86,2)$ & 28 & $(13,8)$ & $203(100)$ & & \\
\hline
\end{tabular}

\section{Analisis Multivariat}

Seleksi Bivariat

Seleksi bivariat merupakan penentuan variabel independen potensial (variabel kandidat multivariat) yang akan masuk kedalam analisis multivariat, yaitu yang mempunyai nilai $\mathrm{p}<0,25$. Dari hasil seleksi bivariat yang telah dilakukan diperoleh hasil bahwa semua variabel mempunyai nilai $\mathrm{p}<0,25$ sehingga semua variabel dalam penelitian ini menjadi kandidat.

Pemodelan Multivariat Akhir

Dari analisis multivariat yang dilakukan 6 kali pemodelan diperoleh hasil bahwa pada tabel 2 berikut : 
Tabel 1 Model Akhir

\begin{tabular}{llccrrr}
\hline No. & \multicolumn{1}{c}{$\begin{array}{c}\text { Variabel } \\
\text { Independen }\end{array}$} & p Value & POR & \multicolumn{3}{c}{$\begin{array}{c}\text { (95\% CI) } \\
\text { for EXP (B) }\end{array}$} \\
\hline 1. & Pengetahuan & $\mathbf{0 , 0 2 1}$ & $\mathbf{2 , 9 3 4}$ & $\mathbf{1 , 1 7 9}$ & - & $\mathbf{7 , 2 9 9}$ \\
2. & Sikap & $\mathbf{0 , 0 0 5}$ & $\mathbf{4 , 0 0 1}$ & $\mathbf{1 , 5 2 7}$ & - & $\mathbf{1 0 , 4 8 1}$ \\
3. & Dukungan Keluarga & $\mathbf{0 , 0 1 8}$ & $\mathbf{2 , 9 5 1}$ & $\mathbf{1 , 2 0 6}$ & - & $\mathbf{7 , 2 2 2}$ \\
4. & Umur & 0,263 & 1,674 & 0,679 & - & 4,126 \\
\hline
\end{tabular}

Tabel 2 di atas menyatakan bahwa adanya 3 variabel yang berhubungan bermakna dengan Pemberian ASI Eksklusif Pada Ibu Yang Memiliki Bayi Umur 6-11 Bulan Di Wilayah Kerja Puskesmas Kecamatan Tambang Tahun 2015 yakni, variabel: Sikap, Pengetahuan dan Dukungan Terdapat Variabel Confounding, yaitu umur confounding dengan Pengetahuan dan Sikap.

\section{PEMBAHASAN}

Hubungan Sikap dengan Pemberian ASI Eksklusif

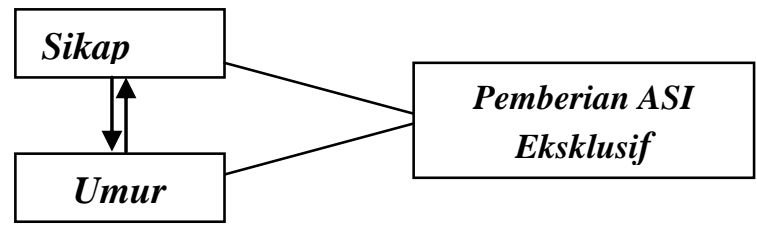

Gambar 1 Hubungan Umur dan Sikap Terhadap Pemberian ASI Eksklusif

Sikap berhubungan sebab akibat dengan pemberian ASI Eksklusif pada Ibu yang memiliki bayi umur 6-11 bulan. Sikap ibu yang negatif akan berpengaruh terhadap pemberian ASI Eksklusif 4 kali untuk tidak memberikan ASI Eksklusif dibandingkan sikap ibu yang positif.

Ibu yang bersikap negatif lebih memilih untuk tidak memerikan ASI Eksklusif pada bayinya karena sikap negatif ibu tersebut akan menentukan kecenderungan prilaku yang tidak mengganggap ASI merupakan makanan yang menjadi satu-satunya makanan yang dibutuhkan bayi selama 6 bulan pertama hidupnya untuk tumbuh dan berkembang menjadi bayi yang sehat.

Fenomena sikap negatif pada ibu menyusui ini dipengaruhi oleh keadaan ibu pada saat proses menyusui. Ibu memiliki anggapan bahwa ASI saja tidak cukup untuk memenuhi kebutuhan nutrisi pada bayi yang berumur 0-6 bulan. Anggapan ini memunculkan sikap negatif pada ibu sehingga ibu memberikan makanan tambahan lain selain ASI secara dini. Selain itu sikap negatif ini dipengaruhi oleh pengalaman ibu saat menyusui dimasa lalu dan masa sekarang.

Ditemukan variabel yang confounding terhadap sikap ibu yaitu, umur confounding dengan sikap.Ini berarti umur berhubungan secara signifikan dengan pemberian ASI Eksklusif dan dengan Sikap ibu.Secara teori umur mempengaruhi Pemberian ASI Eksklusif, karena umur $\geq 30$ tahun memiliki jumlah ASI lebih sedikit dari ibu berumur $<30$ tahun.Hal ini dapat mempengaruhi ibu dalam bersikap untuk memberikan ASI Eksklusif atau tidak.Mengingat besarnya manfaat pemberian ASI Eksklusif maka ibu yang berumur <30 tahun memiliki kesempatan yang besar dalam pemberian ASI Eksklusif pada bayinya dikarenakan jumlah ASI yang lebih banyak.

Ibu yang sudah memasuki umur $\geq 30$ tahun secara rasional sudah jauh lebih matang dalam cara berfikir, melihat manfaat ASI yang sangat besar sehingga seharusnya juga mempengaruhi Sikap dalam memutuskan untuk memberikan ASI Eksklusif pada bayinya.

Hubungan Pengetahuan dengan Pemberian ASI Eksklusif 


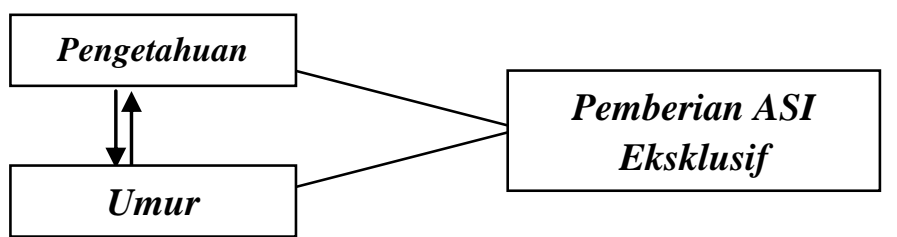

\section{Gambar Hubungan Umur dan Pengetahuan Terhadap Pemberian ASI Eksklusif}

Pengetahuan ibu berhubungan sebab akibat dengan pemberian ASI Eksklusif pada Ibu yang memiliki bayi umur 6-11 bulan. Pengetahuan ibu yang rendah akan berpengaruh terhadap pemberian ASI Eksklusif 3 kali untuk tidak memberikan ASI Eksklusif jika dibandingkan ibu yang memiliki pengetahuan tinggi.

Pengetahuan ibu menyusui terhadap ASI dalam pemberian ASI Eksklusif pada bayi umur 0-6 bulan ini dapat dikatakan masih kurang.Kurangnya pengetahuan ibu tentang ASI Eksklusif ini akan sangat mempengaruhi keberhasilan dalam program pemberian ASI Eksklusif pada bayi umur 0-6 bulan. Sehingga dapat diartikan bahwa ibu yang memiliki pengetahuan rendah tidak memahami betapa pentingnya pemberian ASI Eksklusif pada bayi maupun pada dirinya sendiri sehingga pada akhirnya ibu memutuskan untuk tidak akan memberikan ASI secara Eksklusif.

Ditemukan variabel yang confounding yaitu umur confounding dengan pengetahuan ibu.Ini berarti umur berhubungan secara statisitik signifikan dengan pemberian ASI Eksklusif dan dengan Pengetahuan. Secara rasional bahwa ibu dengan umur $\geq 30$ merupakan umur yang matang dalam berpikir, dengan demikian umur $\geq 30$ tahun cenderung memiliki pengetahuan yang lebih tinggi, sedangkan ibu yang memiliki pengetahuan yang tinggi lebih cenderung memberikan ASI Eksklusif pada bayinya.

\section{Hubungan Dukungan Keluarga dengan Pemberian ASI Eksklusif}

Dukungan Keluarga berhubungan sebab akibat dengan pemberian ASI Eksklusif pada Ibu yang memiliki bayi umur 6-11 bulan. Dukungan Keluarga ibu yang negatif atau tidak mendukung akan berpengaruh terhadap pemberian ASI Eksklusif 3 kali untuk tidak memberikan ASI Eksklusif dibandingkan ibu yang dengan Dukungan Keluarga positif atau mendukung.

Dukungan suami dalam keluarga berperan untuk mendorong ibu dalam pemberian ASI secara Eksklusif kepada bayinya. Dukungan tersebut dapat memberikan manfaat luar biasa kepada ibu yaitu memperlancar produksi ASI dan reflek pengeluaran ASI karena ibu mendapat dukungan secara psikologis dan emosi dari keluarganya. Ibu yang mendapat dukungan dari keluarganya juga akan memiliki motivasi yang sangat kuat dalam memberikan ASI Eksklusif, selain itu ibu juga mendapatkan dukungan ketika ibu mengalami kesulitan pada saat proses menyusui berlangsung.

\section{Faktor Variabel Independen yang tidak berhubungan dengan Pemberian ASI Eksklusif. Dukungan Petugas Kesehatan}

Dalam penelitian ini Dukungan Petugas Kesehatan tidak memiliki hubungan dengan pemberian ASI Eksklusif. Hal ini sangat dimungkinkan karena bisa disebabkan oleh adanya bias informasi, yaitu responden bisa saja lupa dengan apa saja yang sudah dianjurkan oleh petugas kesehatan sehingga responden menyebutkan apa yang dipikirkan saja. Oleh sebab itu untuk peneliti selanjutnya melakukan wawancara sedemikian rupa untuk menghindari terjadinya bias informasi tersebut.

\section{Status Pekerjaan}

Dalam penelitian ini Status pekerjaan tidak memiliki hubungan dengan pemberian ASI Eksklusif.Pada saat ini status pekerjaan tidak lagi menjadi hambatan terhadap pemberian ASI Eksklusif, sehingga dapat dikatakan bahwa ibu menyusui yang bekerja atau tidak bekerja 
tetap bisa memberikan ASI Eksklusif pada bayinya.Hal ini perlu dilakukan penelitian lebih lanjut dengan melihat jenis pekerjaan ibu tersebut.

\section{Paritas}

Dalam penelilitian ini paritas tidak memiliki hubungan dengan pemberian ASI Eksklusif. Ibu dengan paritas primipara dan multipara yang memiliki pengetahuan tentang manfaat ASI Eksklusif akan cenderung memberikan ASI Eksklusif baik itu anak pertama atau anak berikutnya. Perlu dilakukan penelitian lebih lanjut dengan melihat paritas berdasarkan jarak kelahiran anak dan pengalaman atau riwayat pemberian ASI sebelumnya.

\section{Pendidikan}

Pendidikan tidak memiliki hubungan dengan pemberian ASI Eksklusif. Hal ini bisa saja terjadi karena pada saat sekarang memungkinkan untuk segala tingkat pendidikan tetap akan dapat dengan mudah mengakses informasi tentang ASI Eksklusif melalui media massa. Dengan demikian tingkat pendidikan rendah memiliki peluang yang sama dengan ibu yang berpendidikan tinggi untuk mengetahui segala informasi tentang ASI Eksklusif. Untuk peneliti selanjutnya agar melihat kategori berdasarkan jenis pendidikan kesehatan dan non kesehatan.

\section{KESIMPULAN}

Proporsi ibu yang memiliki bayi umur 6-11 bulan dan memberikan ASI Eksklusif di wilayah kerja Puskesmas Kecamatan Tambang Kabupaten Kampar adalah sebanyak 28 orang $(13,8 \%)$.

Variabel yang mempunyai hubungan sebab akibat terhadap pemberian ASI Eksklusif Pada Ibu yang memiliki Bayi umur 6-11 bulan di Wilayah Kerja Puskesmas Kecamatan Tambang Kabupaten Kampar adalah :

Ibu yang memiliki Sikap negatif berhubungan 4 kali pada ibu memiliki bayi umur 611 bulan untuk tidak memberi ASI Eksklusif dibandingkan dengan Ibu yang sikap Positif Ibu yang memiliki Pengetahuan rendah berhubungan 3 kali pada ibu memiliki bayi umur 6-11 bulan untuk tidak memberi ASI Eksklusif dibandingkan dengan Ibu Pengetahuan tinggi.

Ibu yang memiliki Dukungan Keluarga dengan tidak ada dukungan berhubungan 3 kali pada ibu memiliki bayi umur 6-11 bulan untuk tidak memberi ASI Eksklusif dibandingkan dengan Ibu dengan keluarga yang mendukung.

Variabel independen yang merupakan confounding yaitu umur dengan Sikap dan pengetahuan.

Variabel independen yang tidak memiliki hubungan statistik signifikan dengan pemberian ASI Eksklusif pada ibu yang memiliki bayi 6-11 bulan adalah : Petugas Kesehatan, Pekerjaan, Pendidikan dan Paritas.

\section{SARAN}

Bagi Dinas Kesehatan Kampar untuk dapat menjadi pelopor dalam pembentukan Pojok ASI, Kurir dan Ojek ASI sebagai sarana bagi ibu untuk menyusui atau memerah ASI, sehingga ibu menyusui yang bekerja dan lokasi tempat bekerja yang jauh dari rumah tetap dapat memberikan ASI Eksklusif pada bayinya.

Bagi Puskesmas Kecamatan Tambang agar dapat melakukan pembinaan dengan membentuk kelas ibu hamil dan menyusui atau sarana belajar pada bagian KIA/KB dalam memberikan KIE pada ibu sehingga petugas kesehatan dapat melakukan demonstrasi dan membimbing ibu tentang bagaimana cara menyusui yang benar agar ibu bersikap positif terhadap pemberian ASI Eksklusif sehingga dapat meningkatkan jumlah cakupan pemberian ASI Eksklusif.

Bagi Ibu hamil trimester ke III diharapkan untuk lebih meningkatkan pengetahuan tentang persiapan dalam menghadapi proses menyusui dan pemberian ASI secara Eksklusif dengan membentuk komunitas ibu-ibu agar ibu dapat bertukar pendapat dan berbagi 
pengalaman tentang ASI Eksklusif sehingga pengetahuan ibu meningkat dan dapat menurunkan angka kesakitan dan kematian pada ibu dan bayi.

Bagi Keluarga agar dapat mengakses informasi seputar Asi Eksklusif melalui media internet, media sosial, buku atau majalah, dan bagi para suami diharapkan ikut bergabung atau membentuk komunitas Ayah Peduli ASI sebagai sarana untuk meningkatkan pengetahuan sehingga keluarga dapat membantu ibu mengatasi dalam masalah dalam peoses menyusui.

\section{E. DAFTAR PUSTAKA}

Dinkes Riau. (2014). Profil Kesehatan Provinsi RiauPekanbaru: Dinkes Provinsi Riau: Pekanbaru.

Dinkes Kampar. (2012). Profil Kesehatan Kabupaten Kampar: Dinkes Kampar: Kampar. . (2014). Profil Kesehatan Kabupaten Kampar. Dinkes Kampar: Kampar.

Depkes RI. (2012). Glosarium Data \& Informasi Kesehatan. Pusat Data \& Informasi Departemen Kesehatan RI: Jakarta (2004). Asi Eksklusif Untuk Ibu Bekerja.Dirjen Binkesmas Direktorat Gizi Masyarakat: Jakarta.

Lapau, B. 2013.Diktat Metode Penelitian Kesehatan. Buku Obor, Jakarta.

Rahardjo.(2009). Hubungan Antara Pengetahuan Tentang Manfaat ASI Eksklusif Terhadap Motivasi Menyusui Pada Ibu Yang Mempunyai Balita Di Kelurahan Bidara Cina Jakarta Timur.vol 3, Januari 2009 Keperawatau UI: Depok.

Rahmawati, M.D. (2010).Faktor-Faktor Yang Mempengaruhi Pemberian Asi Eksklusif Pada Ibu Menyusui Di Kelurahan Pedalangan Kecamatan Banyumanik Kota Semarang. Jurnal Kesmadaska Vol 1 No. 1 Juli :STIKES Kusuma Husada: Surakarta.

Roesli, U. (2005). Mengenal ASI Eksklusif. Trubus Agriwidya: Jakarta. . (2008). Inisiasi Menyusui Dini Plus ASI Eksklusif. Pustaka Bunda: Jakarta.

STIKes Hang Tuah, (2009).Panduan Karya Ilmiah Magister. STIKes Hang Tuah: Pekanbaru.

UNICEF. (2011). Indonesia's Infant Mortality Rate Still High: UNICEF. http://news.xinhuanet.com/english2010/health/2011-10/06/c131176857.htm. April, 20, 2015.

WHO.(2008). Indicators for Assessing Infant and Young Child Feeding Practice.Genewa. April, 20, 2015. . (2009). Global health risks: Mortality and burden of disease attributable to selected major risks. Diunduh dari: http://www.who.int/healthinfo/global_burden_disease/GlobalHealthRisks_report_full. pdf. April, 20, 2015. . (2012). The Optimal Duration of Eksklusif Bresfedding Mother Report of An Expert Consultation. Geneva: Switzerland. April, 20, 2015. 